\title{
Consentimento Informado na Investigação Clínica em Portugal: Promoção de Boas Práticas
}

\author{
Informed Consent in Clinical Research in Portugal: \\ Promotion of Good Practices
}

\author{
Sílvia MARINA ${ }^{1,2}$, Ivone DUARTE 1,2 , Miguel RICOU $\triangle^{1,2}$ \\ Acta Med Port 2020 Jul-Aug;33(7-8):453-455 - https://doi.org/10.20344/amp.13545
}

Palavras-chave: Confidencialidade/ética; Consentimento Informado; Investigação

Keywords: Confidentiality/ethics; Informed Consent; Research

A investigação nacional tem vindo a crescer exponencialmente nos últimos anos. ${ }^{1}$ É por isso cada vez maior a quantidade de questionários a serem utilizados. $\mathrm{O}$ consentimento informado $(\mathrm{Cl})$ é parte fundamental para uma recolha e posterior utilização dos dados, pelo que merece a maior atenção acerca do rigor que deve ser imposto ao mesmo. Importa sublinhar que em investigação, independentemente do seu importante papel social, os direitos das pessoas assumem uma dimensão ainda mais relevante. Ao contrário do que se verifica nos cuidados de saúde, na investigação são os profissionais que procuram as pessoas. Também por isso, são cada vez mais as revistas científicas que exigem o parecer de uma comissão de ética acerca do estudo em causa podendo a ausência deste impedir a publicação do mesmo.

Várias associações profissionais, inclusive médicas, desenvolveram diretrizes e políticas orientadas a fim de garantir uma conduta apropriada dos investigadores. ${ }^{2}$ No entanto, é frequente, independentemente da área de conhecimento, encontrar-se um $\mathrm{Cl}$ inadequado, apesar das diretivas ${ }^{3}$ existentes nesse sentido. Frequentemente a explicação é insuficiente, e muitas vezes as questões referentes à aceitação da participação no estudo não são de resposta objetiva. Alguns estudos indicam que, na sua maioria, as alterações solicitadas aos protocolos de investigação submetidos às comissões de ética estão também relacionadas com a inadequabilidade do $\mathrm{Cl}^{4,5}$ São indicadas dificuldades na compreensão do $\mathrm{Cl}$ por parte do participante devido à utilização de linguagem demasiado complexa e falta de clarificação dos riscos associados. ${ }^{5}$ Esta pode ser uma barreira para a não-voluntariedade da participação. ${ }^{6}$

Tais factos, como expetável, não permitirão a obtenção de um parecer positivo logo à partida por parte da comissão de ética, podendo impedir que a investigação tenha início nas datas definidas e em último caso inviabilizar a realização do estudo.

$\mathrm{Um} \mathrm{Cl}$ adequado deve apresentar o objetivo do estudo de uma forma clara, com identificação do(s) investigador(es) responsável(is) pelo tratamento dos dados, os seus contactos, e mencionar o âmbito do estudo. Ainda que se trate de um estudo onde apenas se solicita a resposta a um questionário, o consentimento não deve ser considerado tácito a partir da resposta ao mesmo. Ou seja, não se deve assumir que se a pessoa responde ao questionário, então está a dar o seu consentimento, pelo que terá que existir uma questão referente à compreensão e aceitação da participação. O destino a dar ao tratamento dos dados não é, muitas vezes, transparente. Isso deve ser explicitado no $\mathrm{Cl}$ e deve, igualmente, existir uma questão pedindo a autorização do participante para o tratamento e a conservação dos dados por um período bem definido. Ora, sabe-se que o rigor do consentimento informado deve ser assegurado de forma inequívoca. Veja-se o exposto na lei da investigação clínica acerca do consentimento informado. No âmbito da lei da investigação clínica, o consentimento informado é definido como "a decisão expressa de participar num estudo clínico, tomada livremente por uma pessoa dotada de capacidade de o prestar ou, na falta desta, pelo seu representante legal, após ter sido devidamente informada sobre a natureza, o alcance, as consequências e os riscos do estudo, bem como o direito de se retirar do mesmo a qualquer momento, sem quaisquer consequências...."?

Desde o código de Nuremberga, criado em 1947 e constituído por 10 princípios que visam proteger e regulamentar a investigação com pessoas, ${ }^{8}$ o consentimento informado é um dos aspetos mais importantes. A este propósito, também a Declaração de Helsínquia ${ }^{9}$ define princípios éticos que orientam a investigação médica com pessoas. Neste âmbito, a investigação clínica é definida como qualquer investigação que utiliza material ou dados humanos identificáveis, o que pode incluir dados recolhidos sob a forma de questionários. Neste enquadramento, na Declaração de Helsínquia ${ }^{9}$ é defendido que os direitos das pessoas que participam na investigação devem ser salvaguardados, nomeadamente a privacidade e a confidencialidade da informação.

Pretende-se alertar a comunidade científica para a responsabilidade e o dever da obtenção de um consentimento livre e esclarecido, com o rigor que the é merecido no âmbito de qualquer investigação.

\footnotetext{
1. Departamento de Medicina da Comunidade, Informação e Decisão em Saúde. Faculdade de Medicina. Universidade do Porto. Porto. Portugal.

2. Centro de Investigação em Tecnologias e Serviços de Saúde (CINTESIS). Porto. Portugal.

$\square$ Autor correspondente: Miguel Ricou. mricou@med.up.pt

Recebido: 04 de fevereiro de 2020 - Aceite: 23 de março de 2020 | Copyright @ Ordem dos Médicos 2020
} 
Não obstante o tipo de investigação e todos os pressupostos éticos e diretivas que lhes estão subjacentes, de um modo geral e considerando o regulamento (UE) 2016/679 do Parlamento Europeu e do Conselho de 26 de abril de 2016, o consentimento informado deve incluir a informação indicada em cada uma das alíneas apresentadas a seguir. ${ }^{2}$

a) $\mathrm{O} \mathrm{Cl}$ deve ser dado mediante um ato positivo claro que indique uma manifestação de vontade livre, específica, informada e inequívoca de que o titular de dados consente no tratamento dos dados que the digam respeito, seja sob a forma de declaração escrita, oral e inclusive em formato eletrónico. Neste último caso, o consentimento pode ser dado através da validação de uma opção apresentada online, que indique claramente que aceita o tratamento proposto dos seus dados pessoais. Note-se que o silêncio, as opções pré-validadas, ou a omissão, não deverão constituir um consentimento. O participante deve responder sim a uma afirmação, como por exemplo, "depois de ler/ouvir o texto introdutório, considero-me informado(a) e aceito participar neste estudo respondendo a este questionário".

b) O consentimento deverá abranger todas as atividades de tratamento dos dados realizadas. Caso o tratamento sirva para finalidades múltiplas, deverá ser pedido um consentimento para todos esses fins (por exemplo, "concordo que os meus dados sejam tratados no âmbito desta investigação"; "concordo que os resultados do tratamento dos dados sejam divulgados em publicações científicas, assegurando o anonimato"), mesmo que este seja dado no seguimento de um pedido apresentado por via eletrónica. Deve ser permitido aos participantes fornecer o seu consentimento unicamente para determinados domínios da investigação ou partes de projetos de investigação. Tais como, por exemplo, "depois de ler/ ouvir o texto introdutório, considero-me informado(a) e aceito participar neste estudo respondendo a este questionário" e "concordo que os meus dados sejam utilizados para fins de investigação no âmbito deste projeto".

c) A informação fornecida deve ser transparente. Em particular, destacam-se as informações fornecidas aos participantes sobre a identidade do responsável pelo tratamento dos dados, incluindo informação para contacto, o âmbito em que se insere o estudo e os fins a que se destina.

d) As pessoas devem ser informadas acerca da existência de possíveis riscos, regras, garantias e direitos associados, assim como alertadas para os meios de que dispõem para exercer os seus direitos. Caso não existam riscos previstos, isso mesmo deve ser referido.

e) Os dados pessoais solicitados deverão ser adequados, pertinentes e limitados aos fins a que se destinam. Não devem por isso ser solicitados dados que não vão ser utilizados na investigação. Do mesmo modo, deve ser assegurado um prazo de conservação dos dados limitado ao tempo mínimo. Para assegurar que os dados sejam conservados apenas durante o período considerado necessário, o responsável pelo tratamento deverá fixar os prazos para o apagamento ou revisão.

f) Deve ser garantida a segurança e a confidencialidade dos dados. Ou seja, o acesso aos dados ou ao equipamento utilizado para o seu tratamento está devidamente salvaguardado a pessoas não autorizadas. Para além disso, em termos de confidencialidade, quando se tratam de dados recolhidos por via eletrónica o responsável deve adotar medidas técnicas para esse efeito.

g) O participante deve dispor de uma escolha verdadeiramente livre, e para tal devem ser asseguradas as opções de poder recusar ou retirar consentimento, a qualquer momento, sem ser prejudicado.

Pretende-se deste modo sensibilizar e alertar a comunidade científica para o rigor do consentimento informado em investigação. Para tal, por forma a auxiliar os investigadores, sintetizam-se orientações práticas para a edificação de um consentimento informado verdadeiramente livre e esclarecido. Existe um rigor científico cada vez mais crescente e necessário no que à escrita de um artigo diz respeito, em particular quanto à componente metodológica. No entanto, importa considerar que este rigor deve ser atendido aquando da recolha dos dados, iniciando-se com a obtenção do consentimento informado. Neste âmbito, as comissões de ética terão também um papel fundamental aquando da análise dos protocolos de investigação, nomeadamente dos termos em que o consentimento informado é redigido.

No contexto de investigação, contrariamente ao que acontece na prática clínica, é o investigador que procura os participantes, pelo que o respeito pela autonomia do indivíduo será, neste caso, o princípio primordial. O respeito pela autonomia significa que a pessoa tem direito à sua autodeterminação, de agir segundo os seus interesses. Portanto, o $\mathrm{Cl}$ pode entender-se como uma escolha livre e voluntária da pessoa para participar em determinado estudo, depois de fornecidas todas as informações acerca da mesma, assegurando-se que estas foram entendidas.

\section{REFERÊNCIAS}

1. Fundação para Ciência e a Tecnologia. FCT 20 anos a apoiar a ciência e a tecnologia em Portugal. 2020. [consultado 2020 jan 26] Disponível em: https://www.fct.pt/documentos/FCT_20anos versao completa.pdf.

2. Association of Clinical Research Professionals. Code of Ethics and Professional Conduct. 2016. [consultado 2020 mar 10]. Disponível em: www.acrpnet.org/about/code-of-ethics.

3. Regulamento (UE) do Parlamento Europeu e do Conselho relativo à proteção das pessoas singulares no que diz respeito ao tratamento de dados pessoais e à livre circulação desses dados. 2016. [consultado 2020 jan 20]. Disponível em: https://eur-lex.europa.eu/legal-content/PT/ 
TXT/?uri=OJ:L:2016:119:TOC\#TN0001.

4. Lidz CW, Appelbaum PS, Arnold R, Candilis P, Gardner W, Myers S, et al. How closely do institutional review boards follow the common rule? Acad Med. 2012;87:969-74.

5. Chamberlain JM, Lillis K, Vance C, Brown K, Fawumi O, Nichols S, et al. Perceived challenges to obtaining informed consent for a time-sensitive emergency department study of pediatric status epilepticus: results of two focus groups. Acad Emerg Med. 2009;16:763-70.

6. Welch BM, Marshall E, Qanungo S, Aziz A, Laken M, Lenert L, et al. Teleconsent: a novel approach to obtain informed consent for research.
Contemp Clin Trials Commun. 2016:3:74-9.

7. Decreto-Lei $n^{\circ} 21 / 2014$. Diário da República, I série, nº 75 (214/04/16). p.2450-65.

8. Shuster E. Fifty years later: the significance of the Nuremberg code. $\mathrm{N}$ Engl J Med. 1997;337:1430-40.

9. Associação Médica Mundial. Declaração de Helsínquia. Princípios éticos para a pesquisa médica envolvendo seres humanos $-64^{\text {a }}$ Assembleia Geral da WMA. 2013. [consultado 2020 jan 22]. Disponível em: https://arquivos.amb.org.br/_downloads/491535001395167888_ DoHBrazilianPortugueseVersionRev.pdf. 